Inter-rater reliability of medication error classification in a voluntary patient safety incident reporting system HaiPro in Finland

\title{
Holmström, Anna-Riia
}

2019-07

Holmström , A-R , Järvinen , R , Laaksonen , R , Keistinen , T , Doupi , P \& Airaksinen , M 2019 , ' Inter-rater reliability of medication error classification in a voluntary patient safety incident reporting system HaiPro in Finland ' , Research in Social and Administrative Pharmacy, vol. 15 , no. 7 , pp. 864-872 . https://doi.org/10.1016/j.sapharm.2018.11.013

http://hdl.handle.net/10138/307562

https://doi.org/10.1016/j.sapharm.2018.11.013

cc_by_nc_nd

acceptedVersion

Downloaded from Helda, University of Helsinki institutional repository.

This is an electronic reprint of the original article.

This reprint may differ from the original in pagination and typographic detail.

Please cite the original version. 


\section{Accepted Manuscript}

Inter-rater reliability of medication error classification in a voluntary patient safety incident reporting system HaiPro in Finland

Anna-Riia Holmström, Riina Järvinen, Raisa Laaksonen, Timo Keistinen, Persephone Doupi, Marja Airaksinen

PII:

S1551-7411(18)30694-6

DOI:

https://doi.org/10.1016/j.sapharm.2018.11.013

Reference: RSAP 1182

To appear in: Research in Social \& Administrative Pharmacy

Received Date: 1 August 2018

Revised Date: 21 November 2018

Accepted Date: 27 November 2018

Please cite this article as: Holmström AR, Järvinen R, Laaksonen R, Keistinen T, Doupi P, Airaksinen $\mathrm{M}$, Inter-rater reliability of medication error classification in a voluntary patient safety incident reporting system HaiPro in Finland, Research in Social \& Administrative Pharmacy (2018), doi: https:// doi.org/10.1016/j.sapharm.2018.11.013.

This is a PDF file of an unedited manuscript that has been accepted for publication. As a service to our customers we are providing this early version of the manuscript. The manuscript will undergo copyediting, typesetting, and review of the resulting proof before it is published in its final form. Please note that during the production process errors may be discovered which could affect the content, and all legal disclaimers that apply to the journal pertain. 
Inter-rater Reliability of Medication Error Classification in a Voluntary Patient Safety Incident Reporting System HaiPro in Finland

\section{Authors}

Anna-Riia Holmström, MSc (Pharm) ${ }^{1}$

anna-riia.holmstrom@helsinki.fi

Riina Järvinen, MSc (Pharm) ${ }^{1}$

riina.erkkila@gmail.com

Raisa Laaksonen, PhD, Adjunct professor in Clinical Pharmacy ${ }^{1}$ raisa.laaksonen@helsinki.fi

Timo Keistinen, MD, PhD, Ministerial Counsellor ${ }^{2}$

timo.keistinen@stm.fi

Persephone Doupi, PhD, Senior Researcher ${ }^{3}$

persephone.doupi@thl.fi

Marja Airaksinen, PhD, Professor ${ }^{1}$

marjaairaksinen@gmail.com

${ }^{1}$ University of Helsinki, Finland

Viikinkaari 5 E (P.O. Box 56), 00014 Helsingin yliopisto, Finland

${ }^{2}$ Ministry of Social Affairs and Health, Finland

P.O Box 33, 00023 Valtioneuvosto, Finland

${ }^{3}$ National Institute for Health and Welfare, Finland

P.O.Box 30, 00271 Helsinki, Finland

\section{Correspondence:}

Anna-Riia Holmström

Postal address: Faculty of Pharmacy, Viikinkaari 5 E, Po Box 56, 00014 University of Helsinki, Finland

Telephone: +358445747018

Fax: +358919159884

E-mail: anna-riia.holmstrom@helsinki.fi

DECLARATION OF INTEREST: none 
Inter-rater Reliability of Medication Error Classification in a Voluntary Patient Safety Incident Reporting System HaiPro in Finland

\section{ABSTRACT}

Background Medication errors are common in healthcare. Medication error reporting systems can be established for learning from medication errors and risk prone processes, and their data can be analysed and used for improving medication processes in healthcare organisations. However, data reliability testing is crucial to avoid biases in data interpretation and misleading findings informing patient safety improvement. Objective To assess the inter-rater reliability of medication error classifications in a voluntary patient safety incident reporting system (HaiPro) widely used in Finland, and to explore reported medication errors and their contributing factors.

Method The data consisted of medication errors ( $n=32592$ ), including near misses, reported by 36 Finnish healthcare organisations in 2007-2009. The reliability of the original classifications was tested by an independent researcher reclassifying a random sample of errors $(1 \%, n=288)$ based on narratives. The interrater reliability of agreement $(\mathrm{k})$ of the classifications was calculated to describe the degree of conformity between the researcher and the original data classifiers. Descriptive statistics were used to describe the medication errors.

Results The inter-rater reliability between the researcher and the original data classifiers was acceptable $(\mathrm{k}$ $\geq 0.41)$ in 11 of $42(26 \%)$ medication error classes. Thus, these errors could be pooled from different healthcare units for the exploration of medication errors at the level of all reporting organisations. Contributing factors were identified in $48 \%(n=137)$ of the medication error narratives in the random sample $(n=288)$. The most commonly reported errors were dispensing errors $(34 \%, n=10906)$, administration errors $25 \%(n=7972)$, and documentation errors $17 \%(n=5641)$.

Conclusions The data classified by different classifiers can be pooled for some of the medication error classes. Consistency of the classification and the quality of narratives need improvement, as well as reporting and classification of contributing factors to provide high quality information on medication errors. 
Key words: medication error; incident reporting and analysis; medication safety; inter-rater reliability; adverse events 


\section{INTRODUCTION}

Medication errors are one of the most common incidents leading to adverse events in healthcare, occurring with approximately $1-2 \%$ of inpatients worldwide. ${ }^{1}$ Medication errors are defined as any preventable event that may cause or lead to inappropriate medication use or patient harm while the medication is under the control of a healthcare professional, patient, or consumer. ${ }^{2}$ One of the recommended strategies for learning from medication errors and risk prone processes is the establishment of national and local (e.g. hospital or unit based) medication error reporting systems. ${ }^{3}$ These systems are typically databases where healthcare professionals are able to file reports on medication incidents occurring in their daily practice. This data can be further analysed and used for improving medication processes in healthcare organisations.

Some countries have introduced medication error reporting systems into their healthcare systems, but many of them are still maturing. ${ }^{4}$ Currently in Finland, over 200 health- and social care organisations report medication errors, including near misses, in an electronic patient safety incident reporting system HaiPro. ${ }^{5}$ The HaiPro reporting system, launched in 2007 , provides a great amount of information on the data reported and how the organisations have learnt from their incidents and improved their processes of care. The HaiPro system is primarily targeted at internal use in healthcare units, e.g., a paediatric unit within a larger hospital organisation, and hospital pharmacies. The HaiPro system can be accessed online through the organisation's intranet. The reporting process is voluntary and anonymous. It is based on a systems ${ }_{\text {approach; }}{ }^{6}$ both error reporting and data analysis are confidential and blame-free. The HaiPro system also targets to identifying the root causes and contributing factors to errors in the reporting organisation, representing a key feature of a systems approach to error prevention. ${ }^{7}$ Furthermore, HaiPro encourages the organisations to change their erroneous processes and to track the impact of the changes to patient and medication safety. ${ }^{8}$

In addition to serving as a local patient safety promotion tool, HaiPro has the potential to provide information on patient safety incidents at the level of all reporting organisations and so giving information on national medication safety promotion activities. Medication errors reported to HaiPro are classified by 
local data classifiers, e.g., nurses in their respective healthcare organisations. This raises an issue of conformity and inter-rater reliability of the classifications even though the classifiers are given an introduction for classifying the narrative data in the reports. ${ }^{9,10}$ The generally accepted method for assessment of inter-rater reliability is to have two independent reviewers classify the same incidents. ${ }^{10,11}$ The level of agreement between reviewers can then be determined by inter-rater reliability measures indicating the consistency of the ratings. ${ }^{12}$

The aim of this study was to assess the inter-rater reliability of the information reported to HaiPro on medication errors. Similar reliability evaluations have been conducted for other patient safety incident reporting systems. ${ }^{13-15}$ The studies have found that reliability of classification systems of incidents has been a problem and hindering the use of the error data for research. ${ }^{14,15}$ Hence, the studies implicate the need for conducting such evaluations to ensure the quality of the medication error data used for informing the safety improvement strategies of healthcare organisations.

The previous studies have mainly investigated the inter-rater reliability of medication error classification in relation to event type, preventability, and outcome severities. ${ }^{14-16}$ To our knowledge, this is the first study, in which the inter-rater reliability assessment covers all the classified information reported on medication errors in a patient safety incident reporting system. Based on the findings, recommendations will be suggested for improving the medication error reporting and classification processes of HaiPro and for similar systems in other countries to produce more reliable and high quality information on risky medication processes.

\section{METHODS}

\section{Data and ethical approval}

The data comprised of all the patient safety incidents ( $n=64405$ ) reported to the HaiPro Incident Reporting System by personnel in 36 Finnish healthcare organisations during the pilot phase of HaiPro in 2007-2009. The majority of the reporting organisations provided specialized secondary and tertiary healthcare services. The total number of reporting units within these organisations was 2090 and the number of healthcare 
professionals able to file reports was approximately $52000 .{ }^{17}$ During the pilot phase of Haipro, no hospital pharmacies were included in the reporting process; the hospital pharmacies have joined the reporting system afterwards.

The HaiPro reporting process utilises an electronic data collection form in which structured and narrative information on the incident are reported by a healthcare professional (Appendix 1). ${ }^{8,18}$ The hospital units are able to classify and monitor their own incidents; after the incident has been reported in the hospital unit, a local data classifier, usually a unit nurse, classifies the narrative information by using a separate structured electronic data classification form (Appendix 1). The structured data and the classified information from the narratives are then analysed by the data classifiers. ${ }^{8}$

This study concentrated on 32592 medication errors, including near misses, within the pool of all patient safety incidents ( $n=64405$ ). The original data were stored in the databases of the reporting organisations. With their permission the data on these databases were pooled to form a single Excel-database for analysis.

The approval for using the data for research was sought from the reporting organisations by the HaiPro Steering Committee which then granted permission to use the medication error data for the present study. An ethical approval was obtained through the ethical review process of the Vaasa Hospital District, Finland.

\section{Assessment of inter-rater reliability}

The narrative parts of the medication error reports ${ }^{18}$ had been classified by different data classifiers in their respective organisations. The inter-rater reliability of the classifications was evaluated to indicate which elements of the narrative information could be pooled to form a larger data set for analysing medication errors at the level of all reporting organisations. For this purpose, a random sample of $1 \%$ $(n=302)$ of errors was drawn from the data on medication errors ( $n=32592)$ by using the PASW 18.0 software (Figure 1). Errors not related to medications ( $n=14)$ were removed from the random sample. The process of inter-rater reliability testing is presented in Figure 1. 
The inter-rater reliability of the classifications was evaluated by one researcher (RJ) re-classifying the random sample of medication errors $(n=288)$ (Figure 1). The process was two-staged; in the first stage the classification method used by the researcher (RJ) was standardised by using another independent researcher (ARH). For this purpose, a systematic random sample of every third error $(n=96)$ was drawn from the random sample and was re-classified by two researchers (RJ and ARH) (Figure 1). Following this, the inter-rater reliability of agreement between the researchers was measured using the PASW 18.0. statistical software. The researchers and the original data classifiers used the same classification form comprising 96 variables with different values (e.g. variable "nature of the error" had values: 1=near miss, $2=a c t u a l$ error); each of the values was a yes/no selection in the classification process.

Before classifying the systematic random sample of medication errors, the researchers reviewed the classification instructions provided to the original data classifiers. A few clarifications were made to the original instructions to enable thorough classification of the random sample of medication errors. The classification process was based on the researchers' in-depth understanding about the systems approach to medication error prevention, as well as their many years' research and practical experience and conducted studies in the area of medication error reporting and medication safety.

In the second stage of the re-classification process, the first researcher (RJ) independently classified the remaining medication error narratives $(n=192)$ in the random sample (Figure 1). Following this, classifications made by the first researcher (RJ) were compared to the classifications of the original data classifiers to test the reliability of the whole data on medication errors.

The inter-rater reliability was measured by using Cohen's kappa ( $\mathrm{k}$ ) to describe the degree of conformity between the two researchers (RJ and $A R H)$, as well as between the study researcher (RJ) and the original data classifiers. ${ }^{12}$ Cohen's kappa is the most commonly used statistic for categorical items to measure the agreement between two reviewers in studies of patient safety incidents. ${ }^{10,12}$ The degree of agreement by the reviewers is established by interpreting the kappa value. In the present study, the degree of agreement was considered acceptable when resulting in kappa values of 0.41 or above. ${ }^{19}$ 
The kappa values for some of the variables in the systematic random sample of 96 medication errors were low (see Table 1; $\mathrm{k}$ I) when calculating inter-rater reliability between the study researchers (Figure 1). Consequently, the classification instructions were revised to better standardise the classification process. Following this, both researchers independently reviewed their own classifications by using the revised classification instructions (Figure 1).

\section{Description of the medication errors}

Descriptive statistics were used for describing the reported medication errors. The variables with a high enough agreement rate $(\kappa \geq 0.41)$ were described at the level of the entire data ( $n=32$ 592) (Figure 1). ${ }^{12,20}$ The variables with $\mathrm{k}<0.41$ were described at the level of the random sample $(n=288)$ based on classifications made by the researcher (RJ). Cross-tabulation and frequencies were used to present the results. The analyses were performed through the use of Microsoft Excel and PASW 18.0. statistical software.

\section{RESULTS}

\section{Inter-rater agreement of medication error classifications}

The agreement rate between the two researchers (RJ and ARH) was acceptable ( $k \geq 0.41)$ for 40 out of 41 variables for which the kappa value was possible to be calculated in the random sample of medication errors ( $n=288$ ) (Table 1). Between the researcher (RJ) and the original data classifiers the acceptable rate of agreement was achieved for 11 out of 42 variables. Thus, these medication error variables were classified with such a degree of consistency by the classifiers in different reporting healthcare organisations that it is possible to analyse them descriptively in the whole data set ( $n=32592)$ (Figures 2 and 3 ). These 11 variables were related to: the nature of the error; the type of the error; medication documentation errors; dispensing errors; administration errors, and storage errors. However, for storage errors confidence intervals resulted in poor values. 
The degree of conformity between the study researcher (RJ) and the original classifiers did not reach the agreed acceptable level for the majority of the variables on medication errors (Table 1). The researchers were also able to identify more circumstances and contributing factors in the medication error narratives than the original data classifiers had classified (Figure 4). The data with acceptable level of agreement and the conditions and contributing factors to medication errors are presented in the following.

\section{Data with an acceptable level of agreement}

Almost half of the reported medication errors ( $n=32592)$ were actual errors by their nature and the other half were near misses (Figure 2). While the error type (e.g., a dispensing error) was reported for $82 \%$ ( $n=26$ 680) of all errors, it was unknown for $18 \%$ ( $n=5912$ ). The majority of the reported medication errors and near misses were dispensing errors at the units (33\%, $n=10906)$, administration errors $(24 \%, n=7972)$ and medication documentation errors $(17 \%, n=5641)$. Figure 3 shows the most frequent types of medication errors identified.

\section{Conditions and contributing factors}

Conditions and contributing factors to medication errors resulted in low level of agreement and are therefore presented at the level of the random sample $(n=288)$ based on the classifications by the researcher (RJ). The working conditions at the time of the error and other contributing factors were described for half $(48 \%, \mathrm{n} / \mathrm{N}=137 / 288)$ of the reported medication errors. The most common contributing factors were: deficiencies in communication and flow of information between healthcare professionals or units involved in patient care $(53 \%, \mathrm{n} / \mathrm{N}=72 / 137)$; deficiencies in working patterns ( $34 \%, \mathrm{n} / \mathrm{N}=46 / 137)$, and deficiencies in work environment, tools and resources $(33 \%, \mathrm{n} / \mathrm{N}=45 / 137)$. However, contributing factors associated with the organisation and leadership were not reported for any errors. The frequencies of other contributing factors were: inadequate training, introduction and competence of healthcare personnel (12\%, $\mathrm{n} / \mathrm{N}=17 / 137)$; patient and his/her carer (12\% $\mathrm{n} / \mathrm{N}=16 / 137)$; medicines (9\%, $\mathrm{n} / \mathrm{N}=12 / 137)$; deficiencies in team work $(4 \%, n / N=6 / 137)$, and devices or instruments $(1 \%, n / N=2 / 137)$. Other data on consequences to 
hospital unit and the patient and the situation management and immediate actions that remained low in inter-rater reliability are not presented in this paper.

\section{DISCUSSION}

HaiPro is a unique reporting system and a comprehensive tool for healthcare organisations to improve their patient safety and medication processes. The study shows that information on the nature and type of medication errors, and the sub-types of medication documentation, dispensing and administration errors could be pooled from different healthcare units for their exploration at the level of all healthcare organisations using HaiPro. The study indicates that the reporting and classification of error circumstances and contributing factors need to be improved to provide more detailed system-based information for medication safety promotion activities in the reporting healthcare organisations.

Many variables, e.g., outcomes of medication errors to a patient and hospital organisation, had low in interrater reliability between the researcher and the original data classifier. This indicates the need to improve the quality and conformity of medication error reports and their classification. In this task, obtaining comprehensive narratives on reported medication errors is key; many narratives in the current data did not have enough information to enable complete classification of the error or to identify contributing factors. Moreover, in $18 \%$ of the narratives the type of the medication error was not reported, or the data classifier was not able to identify the type of the error. Also, the circumstances and contributing factors could be classified for only a half of the reported errors in our sample as the narratives did not always provide the necessary information. These findings call for educational actions to ensure that all healthcare personnel understand why reporting of errors is necessary and what information needs to be reported to identify unsafe medication processes and to plan safety improvements. ${ }^{21,22}$ The findings may also reflect the inherent limitations of retrospective incident analysis where immediate factors (such as a defective infusion pump) are more easier to identify than the distal factors (such as poor leadership). ${ }^{23}$ Similar findings have been reported for other incident reporting systems with a large number of reporting fields left empty, resulting in loss of necessary information. ${ }^{13,24}$ Further research is needed to determine whether filing 
incomplete reports is primarily a competence issue or the result of a lack of time or motivation for reporting. ${ }^{4,25}$

According to this study, the data classifiers could benefit from additional guidance or training especially concerning the classification of medication error circumstances and contributing factors. Classification of these variables did not reach an acceptable level of conformity between the researcher and the original data classifiers. The researchers were also able to identify and classify more circumstances and contributing factors from the same narratives than the original data classifiers. This may reflect the researchers' more comprehensive understanding about systems approach as a theoretical framework for error prevention and, therefore, enable them to explore the contributing factors in the medication error narratives in more detail. Furthermore, understanding the systems approach enables the identification of the possible contributing factors in the healthcare organisation as a system instead of solely focusing on individual personnel members, e.g., their lack of competence. ${ }^{7}$ Consequently, it must be ensured that the reporting personnel and the data classifiers have sufficient understanding of the systems approach, in order to provide the needed information for healthcare organisations to plan system based actions for medication error prevention. In addition to the competence issues of healthcare staff, the lack of cultural maternity of the reporting organisation may contribute to poor incident reports and their classification although the reporting system itself would espouse the systems approach. ${ }^{25}$ These findings may contribute to underuse of the HaiPro system and possibly similar systems in other countries in detecting circumstances and contributing factors to incidents. These aspects should be noted by the hospital management level when allocating the required resources for incident reporting. ${ }^{25,26}$

The achieved conformity of classifications between the two study researchers indicates that it is possible to classify the medication errors in a unanimous way by developing and using a detailed standard method for classifications and by basing the classification on the systems theory. ${ }^{6}$ The additions made to the HaiPro data classification instructions in our study may also explain the higher conformity achieved between the researchers. Therefore, improving the unambiguity of the classification instructions and standardising the 
classification process to the highest extent possible, may provide one solution for increasing the inter-rater reliability of classifications. Furthermore, the reporting form and procedure should be designed appropriately to enable functional reporting. ${ }^{25,27}$ From the pharmacy practice perspective, it should also be considered whether the pharmacists would be the best suited healthcare professionals for classifying the medication error data and participating the healthcare teams driving the safety improvements.

Our findings support the need for improving the dispensing, administration and medication documentation stages of the medication process in hospitals. ${ }^{26,28}$ In approximately a quarter of the reported errors the medication was "not documented", "not dispensed" or "not administered" to a patient. These all represent an error of omission, increasing the risk of the patient being left without the prescribed medication. ${ }^{29}$ Consequently, our findings show the need to decrease this type of risk which has been identified as the most common medication process-related risk in healthcare organisations. ${ }^{30}$

\section{Strengths and Limitations}

The random sample of incidents included only a few less reported medication error types (e.g., errors in prescribing and preparing medications for administration), possibly due to under-reporting of these errors. This may have influenced on the validity of the reliability testing. Hence, it was not possible to calculate the kappa-value for these error types. Additional research employing inter-rater reliability testing is needed especially for data samples of less reported medication errors to draw final conclusions about the quality of medication error classifications in HaiPro.

The data set was not drawn from all healthcare organisations in Finland; only a number of the organisations participated in the HaiPro pilot programme in 2007-2009 with the majority of them being special healthcare units. However, our study provides preliminary results of the reliability of the medication error classifications in the HaiPro and recommendations for designing and improving similar systems in other countries.

The methods employed in this study proved to be rather time-consuming. Plenty of standardisation was required between the researchers to gain the required level of conformity when classifying the medication 
errors. Thus, trained data classifiers familiar with the operational environments of the reporting hospital units are recommended to be used in future studies instead of researchers who may tend to be "neutral" or "academic" in relation to the actual everyday practice in healthcare where the errors occur and are classified.

\section{Recommendations}

The findings of this study provide central information for designing, implementing and managing medication incident reporting systems. First of all, learning from medication errors requires reliable reporting. ${ }^{31}$ Therefore, from the research perspective, it is recommended to conduct similar evaluations, as described in our study, on other patient and medication safety incident reporting systems as a part of quality assurance of the produced data. Data reliability testing is crucial, especially for systems collecting reports from different healthcare organisations, to avoid biases in data interpretation and misleading findings informing patient safety improvement actions. Data reliability testing and a standard system for incident classification might also benefit the local reporting in healthcare organisations, especially when multiple data classifiers exist. The findings of this study may also be regarded as equally valuable for incident reporting systems in community pharmacies. Indeed, it would be most effective to use the same reporting system and database in both hospital and community settings to maximize the learning opportunities from errors.

For future research studies, some additional methods, such as consensus panels for those classifying the incidents, ${ }^{16}$ is recommended to be included to complete the reliability testing. Observational studies may also be needed to determine the actual occurrence of medication errors and near misses, and their contributing factors. ${ }^{32}$

\section{CONCLUSIONS}

The nature of a medication error; the type of the error; medication documentation errors; dispensing errors, and administration errors can be pooled from different healthcare units for exploration of medication errors at the level of all organisations using HaiPro in Finland. Comprehensive medication error 
narratives providing sufficient and detailed information are key, and need to be targeted by educational efforts for the reporting personnel. It must be ensured that the data classifiers have sufficient understanding of the systems approach to error prevention and skills to classify the medication error narratives, especially in relation to circumstances and contributing factors which may lead to errors.

\section{ACKNOWLEDGEMENTS}

The authors wish to thank the Finnish Cultural Foundation for financial support to the study. We also thank Mr. Richard Stevenson for reviewing the final article for its readability.

\section{FUNDING}

This work was supported by the Finnish Cultural Foundation [00150248 to AR.H].

\section{REFERENCES}

1. Kohn LT, Corrigan JM, Donaldson MS. To Err Is Human: Building a Safer Health System. Washington, D.C.: National Academy Press; 2000.

2. National Coordinating Council for Medication Error Reporting and Prevention. About medication errors: What is a medication error? http://www.nccmerp.org/about-medication-errors. Published 2018. Accessed November 21, 2018.

3. World Health Organization. WHO Draft Guidelines for Adverse Event Reporting and Learning Systems. http://apps.who.int/iris/handle/10665/69797. Published 2005. Accessed November 21, 2018.

4. Holmström A-R, Airaksinen M, Weiss M, Wuliji T, Chan XH, Laaksonen R. National and local medication error reporting systems: a survey of practices in 16 countries. J Patient Saf. 2012;8(4):165-176. doi:10.1097/PTS.0b013e3182676cf3.

5. Awanic Ltd. Reporting System for Safety Incidents in Health Care Organizations. http://www.haipro.fi/eng/. Published 2016. Accessed November 21, 2018. 
6. Reason J. Human error: models and management. West J Med. 2000;172(6):393-396.

7. Waterson P. A critical review of the systems approach within patient safety research. Ergonomics. 2009;52(10):1185-1195. doi:10.1080/00140130903042782.

8. Awanic Ltd. Handling of a patient safety incident report in the HaiPro system.

http://awanic.com/haipro/eng/wordpress/wp-

content/uploads/2015/06/HaiPro_prosessikuva_eng3.pdf. Published 2015. Accessed November 21, 2018.

9. Walshe K. Adverse events in health care: issues in measurement. Qual Health Care. 2000;9:47-52.

10. Kunac DL, Reith DM, Kennedy J, Austin NC, Williams SM. Inter- and intra-rater reliability for classification of medication related events in paediatric inpatients. Qual Saf Health Care. 2006;15(3):196-201. doi:10.1136/qshc.2005.014407.

11. Morimoto T. Adverse drug events and medication errors: detection and classification methods. Qual Saf Heal Care. 2004;13(4):306-314. doi:10.1136/qshc.2004.010611.

12. Howell D. Statistical Methods for Psychology. 8th ed. Belmont, USA: Cengage Learning; 2013.

13. Doupi P. National Reporting Systems for Patient Safety Incidents. A Review of the Situation in Europe. http://www.thl.fi/documents/10531/104907/Report 2009 13.pdf. Published 2009. Accessed November 21, 2018.

14. Snyder RA, Abarca J, Meza JL, Rothschild JM, Rizos A, Bates DW. Reliability evaluation of the adapted National Coordinating Council Medication Error Reporting and Prevention (NCC MERP) index. Pharmacoepidemiol Drug Saf. 2007;16(May):1006-1013. doi:10.1002/pds.

15. Forrey R, Pedersen C, Schneider P. Interrater agreement with a standard scheme for classifying medication errors. Am J Heal Pharm. 2007;64(2):175-181.

16. Van Doormaal JE, Mol PGM, Van Den Bemt PMLA, et al. Reliability of the assessment of preventable adverse drug events in daily clinical practice. Pharmacoepidemiol Drug Saf. 2008;17:645-654. 
doi:10.1002/pds.

17. Ruuhilehto K, Kaila M, Keistinen T, Kinnunen M, Vuorenkoski L, Wallenius J. HaiPro--what was learned from patient safety incidents in Finnish health care units in 2007 to 2009 ? [Abstract in English]. Duodecim. 2011;127:1033-1040.

18. Awanic Ltd. HaiPro - Patient safety incident report.

http://83.150.87.4/haipro/20/lomake.asp?kieli=ENG. Published 2015. Accessed November 21, 2018.

19. Fleiss J, Levin B, Paik M. Statistical Methods for Rates and Proportions. 3rd ed. New Jersey: John Wiley \& Sons Inc.; 2003.

20. Smith F. Research Methods in Pharmacy Practice. London: Pharmaceutical Press; 2002.

21. Brunsveld-Reinders AH, Arbous MS, Vos RDE, Jonge EDE. Incident and error reporting systems in intensive care : a systematic review of the literature. Int J Qual Heal Care. 2016;28(December 2015):2-13. doi:10.1093/intqhc/mzv100.

22. Williams SD, Phipps DL, Ashcroft D. Examining the attitudes of hospital pharmacists to reporting medication safety incidents using the theory of planned behaviour. Int I Qual Health Care. 2015;27(4):297-304.

23. Mahajan RP. Critical incident reporting and learning. Br J Anaesth. 2010;105(1):69-75. doi:10.1093/bja/aeq133.

24. Armitage G, Newell R, Wright J. Improving the quality of drug error reporting. J Eval Clin Pract. 2010;16(6):1189-1197. doi:10.1111/j.1365-2753.2009.01293.x.

25. Holmström A, Laaksonen R, Airaksinen M. How to make medication error reporting systems work Factors associated with their successful development and implementation. Health Policy (New York). 2015;119(8):1046-1054.

26. Cousins DH, Gerrett D, Warner B. A review of medication incidents reported to the National Reporting and Learning System in England and Wales over 6 years (2005-2010). Br J Clin Pharmacol. 
2012;74(4):597-604. doi:10.1111/j.1365-2125.2011.04166.x.

27. Ashcroft BDM, Morecroft C, Parker D, Noyce P. Reporting, reflecting on and learning from adverse events in community pharmacy : development and evaluation of an incident reporting form. Pharm J. 2005;274(May):615-617.

28. James KL, Barlow D, McArtney R, Hiom S, Roberts D, Whittlesea C. Incidence, type and causes of dispensing errors: a review of the literature. Int J Pharm Pract. 2009;17(1):9-30.

29. Cohen M. Medication Errors. 2nd ed. Washington, D.C.: American Pharmacists Association; 2007.

30. Lisby M, Nielsen LP, Mainz JAN. Errors in the medication process : frequency, type, and potential. Int J Qual Heal Care. 2005;17(1):15-22.

31. Williams SD, Ashcroft DM. Medication errors: how reliable are the severity ratings reported to the national reporting and learning system? Int J Qual Heal Care. 2009;21(5):316-320.

32. Flynn EA, Barker KN, Pepper GA, Bates DW, Mikeal RL. Comparison of methods for detecting medication errors in 36 hospitals and skilled-nursing facilities. Am J Heal Pharm. 2002;59(5):436446. 


\section{ACCEPTED MANUSCRIPT}

Table 1 Inter-rater reliability of medication error classifications in the random sample of medication errors $(\mathrm{n}=288)$ for which the kappa ( $\mathrm{k})$ was able to be calculated*. $\mathrm{k}(\mathrm{I})$ describes the agreement between two independent researchers and $\mathrm{k}$ (II) stands for the agreement between the researcher and the original data classifiers. Acceptable agreement rates $(\kappa \geq 0.41)$ are in bold. Each classification is a yes/no selection in the used classification system.

\begin{tabular}{|c|c|c|}
\hline \multirow[t]{2}{*}{ Classification } & $\begin{array}{l}\text { Agreement between two } \\
\text { independent researchers }\end{array}$ & $\begin{array}{l}\text { Agreement between the } \\
\text { researcher and the original } \\
\text { data classifiers }\end{array}$ \\
\hline & $\begin{array}{c}\mathrm{k}(95 \% \mathrm{Cl}) \\
n=96\end{array}$ & $\begin{array}{c}\mathrm{k}(95 \% \mathrm{Cl}) \\
n=x^{*}\end{array}$ \\
\hline \multicolumn{3}{|l|}{ Nature and type of the medication error } \\
\hline $\begin{array}{l}\text { Nature of the error (near miss or } \\
\text { actual error) }\end{array}$ & $0.81(0.71$ to 0.92$)$ & $\begin{array}{c}0.83(0.76 \text { to } 0.90) \\
n=242\end{array}$ \\
\hline Type of the error known & $0.49(-0.12$ to 1.10$)$ & $\begin{array}{l}0.21 \text { (0.06 to } 0.35) \\
n=288\end{array}$ \\
\hline Type of the error & $0.81(0.72$ to 0.91$)$ & $\begin{array}{l}0.63 \text { (0.56 to 0.69) } \\
n=284\end{array}$ \\
\hline $\begin{array}{l}\text { Type of dispensing error (at the unit) } \\
\text { known }\end{array}$ & $0.86(0.76$ to 0.97$)$ & $\begin{array}{c}0.67(0.58 \text { to } 0.75) \\
n=288\end{array}$ \\
\hline Type of the dispensing error & $0.82(0.70$ to 0.93$)$ & $\begin{array}{c}0.67(0.58 \text { to } 0.74) \\
n=280\end{array}$ \\
\hline Type of administration error known & $0.85(0.74$ to 0.97$)$ & $\begin{array}{c}0.67(0.56 \text { to } 0.77) \\
(n=287)\end{array}$ \\
\hline Type of the administration error & $0.83(0.72$ to 0.94$)$ & $\begin{array}{l}0.57(0.47 \text { to } 0.68) \\
n=286\end{array}$ \\
\hline
\end{tabular}


ACCEPTED MANUSCRIPT

\begin{tabular}{|c|c|c|}
\hline $\begin{array}{l}\text { Type of medication documentation } \\
\text { error known }\end{array}$ & $0.85(0.74$ to 0.97$)$ & $\begin{array}{c}0.65(0.54 \text { to } 0.76) \\
n=280\end{array}$ \\
\hline $\begin{array}{l}\text { Type of the medication } \\
\text { documentation error }\end{array}$ & $0.85(0.74$ to 0.96$)$ & $\begin{array}{c}0.59(0.49 \text { to } 0.69) \\
n=288\end{array}$ \\
\hline Type of storage error known & $0.66(0,04$ to 1.28$)$ & $0.57(0.125$ to 1.00$)$ \\
\hline $\begin{array}{l}\text { Type of the storage error (e.g. wrong } \\
\text { storage conditions) }\end{array}$ & $0.66(0,04$ to 1.28$)$ & $\begin{array}{l}0.66(n=287) \\
(0.22 \text { to } 1.10)\end{array}$ \\
\hline Type of prescription error known & $0.66(0.22$ to 1.10$)$ & $\begin{array}{c}0.65(0.43 \text { to } 0.88) \\
n=288\end{array}$ \\
\hline \multicolumn{3}{|l|}{ Outcome for the patient } \\
\hline Outcome for the patient known & $0.66(0.50$ to 0.82$)$ & $\begin{array}{l}0.08(-0.02 \text { to } 0.17) \\
(n=288)\end{array}$ \\
\hline Patient harmed & $0.68(0.56$ to 0.81$)$ & $\begin{array}{l}0.21 \text { (0.13 to } 0.29) \\
(n=288)\end{array}$ \\
\hline $\begin{array}{l}\text { Severity of the outcome to the } \\
\text { patient }\end{array}$ & $0.36(0.17$ to 0.56$)$ & $\begin{array}{l}0.18(0.08 \text { to } 0.29) \\
(n=286)\end{array}$ \\
\hline \multicolumn{3}{|l|}{ Outcome for the hospital unit } \\
\hline Outcome for the unit known & $0.59(0.43$ to 0.75$)$ & $\begin{array}{l}0.06(-0.03 \text { to } 0.15) \\
(n=288)\end{array}$ \\
\hline The error caused harm to the unit & $0.60(0.46$ to 0.73$)$ & $\begin{array}{l}0.10 \text { (0.03 to } 0.19) \\
(n=288)\end{array}$ \\
\hline Image harm to the unit & $0.54(0.37$ to 0.70$)$ & $\begin{array}{l}0.07(-0.01 \text { to } 0.14) \\
(n=288)\end{array}$ \\
\hline Material loss & $0.52(0.36$ to 0.69$)$ & $0.07(-0.02$ to 0.15$)$ \\
\hline
\end{tabular}




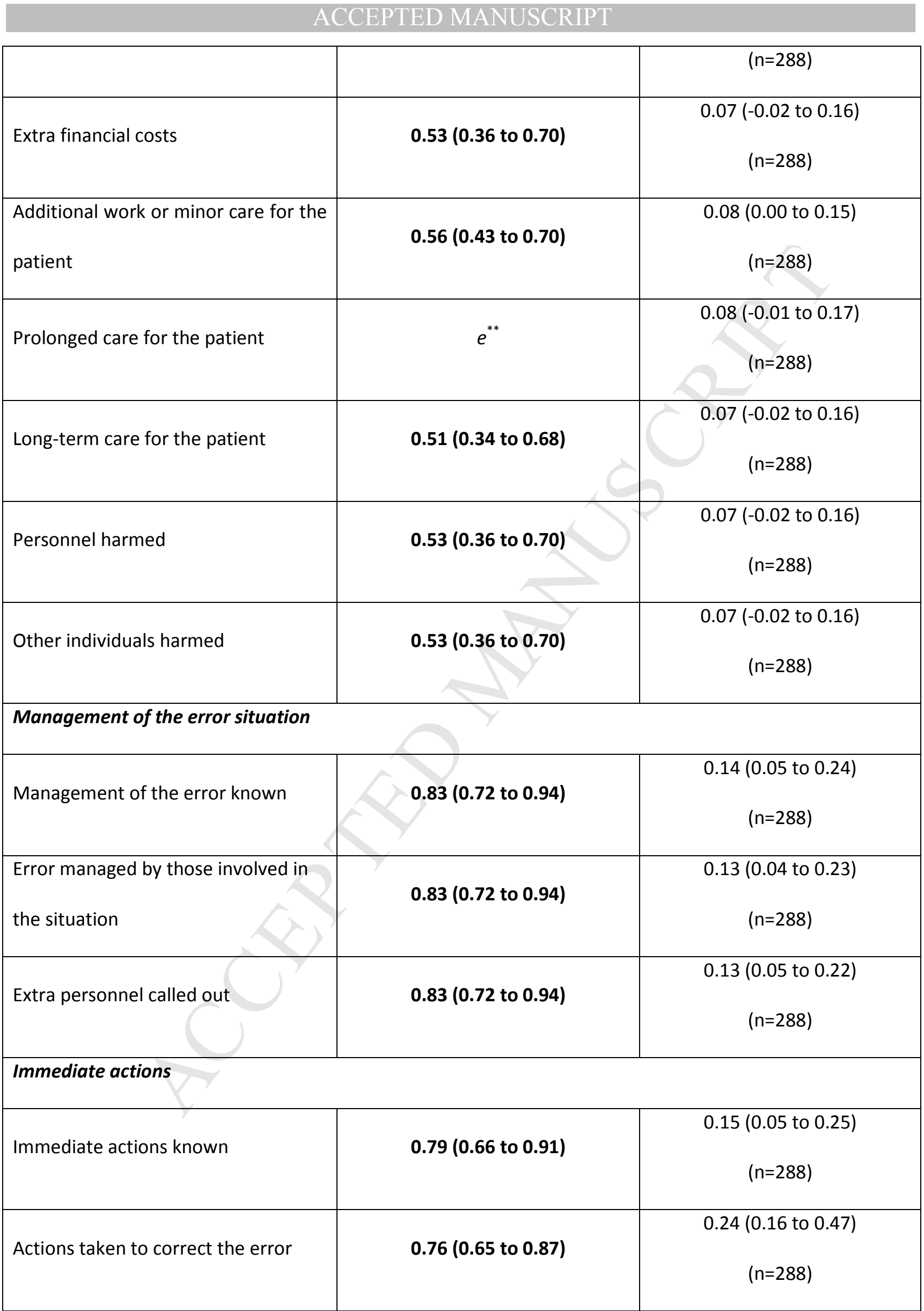




\begin{tabular}{|c|c|c|}
\hline Patient observed and/or informed & 0.75 (0.63 to 0.87$)$ & $\begin{array}{l}0.22(0.13 \text { to } 0.30) \\
(n=288)\end{array}$ \\
\hline $\begin{array}{l}\text { Actions taken to mitigate the effects } \\
\text { of and additional harm caused by the } \\
\text { error }\end{array}$ & $0.60(0.46$ to 0.74$)$ & $\begin{array}{l}0.16(0.08 \text { to } 0.24) \\
(n=288)\end{array}$ \\
\hline \multicolumn{3}{|c|}{ Working conditions and other contributing factors } \\
\hline $\begin{array}{l}\text { Conditions and other contributing } \\
\text { factors known }\end{array}$ & $0.79(0.67$ to 0.91$)$ & $\begin{array}{c}0.22(0.11 \text { to } 0.43) \\
(n=288)\end{array}$ \\
\hline $\begin{array}{l}\text { Communication and flow of } \\
\text { information }\end{array}$ & $0.72(0.60$ to 0.84$)$ & $\begin{array}{l}0.21(0.15 \text { to } 0.30) \\
(n=288)\end{array}$ \\
\hline Working patterns & $0.68(0.56$ to 0.80$)$ & $\begin{array}{c}0.15(0.06 \text { to } 0.24) \\
(n=288)\end{array}$ \\
\hline $\begin{array}{l}\text { Work environment and tools, } \\
\text { resources }\end{array}$ & $0.77(0.66$ to 0.88$)$ & $\begin{array}{l}0.22(0.13 \text { to } 0.32) \\
(n=288)\end{array}$ \\
\hline Patient and his/her carer & $0.74(0.62$ to 0.86$)$ & $\begin{array}{c}0.23(0.13 \text { to } 0.33) \\
(n=288)\end{array}$ \\
\hline $\begin{array}{l}\text { Education and orientation, } \\
\text { competence of personnel }\end{array}$ & $0.76(0.63$ to 0.88$)$ & $\begin{array}{l}0.23(0.13 \text { to } 0.33) \\
(n=288)\end{array}$ \\
\hline Medicines & $0.75(0.63$ to 0.87$)$ & $\begin{array}{l}0.20(0.09 \text { to } 0.30) \\
(n=288)\end{array}$ \\
\hline Team or group work & $0.74(0.61$ to 0.87$)$ & $\begin{array}{l}0.19(0.08 \text { to } 0.30) \\
(n=288)\end{array}$ \\
\hline Devices or instruments & $0.80(0.68$ to 0.92$)$ & $\begin{array}{l}0.20(0.09 \text { to } 0.31) \\
(n=288)\end{array}$ \\
\hline Organisation and leadership & $0.79(0.67$ to 0.91$)$ & 0.21 (0.09 to 0.32$)$ \\
\hline
\end{tabular}




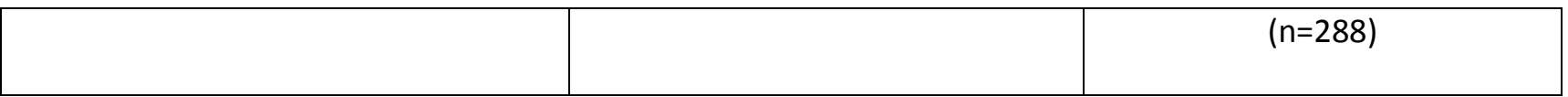

Footnotes:

Interpretation of the kappa-values: 1.00 complete agreement; $0.81-1.00$ almost perfect agreement; $0.61-$ 0.80 substantial agreement, $0.41-0.60$ moderate agreement, $0.21-0.40$ fair agreement; $0.00-0.20$ slight agreement, and $<0.00$ poor agreement or less than agreement by chance.

* Some classifications which prevented the calculation of the kappa were removed as only one of the reviewers had used some specific value related to the classification, resulting in a varying number $(n)$ of classifications

${ }^{* *}$ Calculation not possible as only one of the reviewers has used the classification 
Figure 1 The phases related to handling and analysis of the data from the HaiPro Incident Reporting System.

Figure 2 The reported medication errors as percentages in the data set $(n=32592)$ from the different healthcare organisations using the HaiPro system.

Figure 3 Defined types of the most frequent medication errors in the data ( $n=32$ 592) from different healthcare organisations using the HaiPro system. The level of inter-rater agreement was found acceptable $(\kappa \geq 0.41)$ for the presented error types.

Figure 4 An example of the contributing factors classified by the original data classifier and the researcher based on the narrative of a medication error reported by a personnel member in a hospital unit using the HaiPro system. 


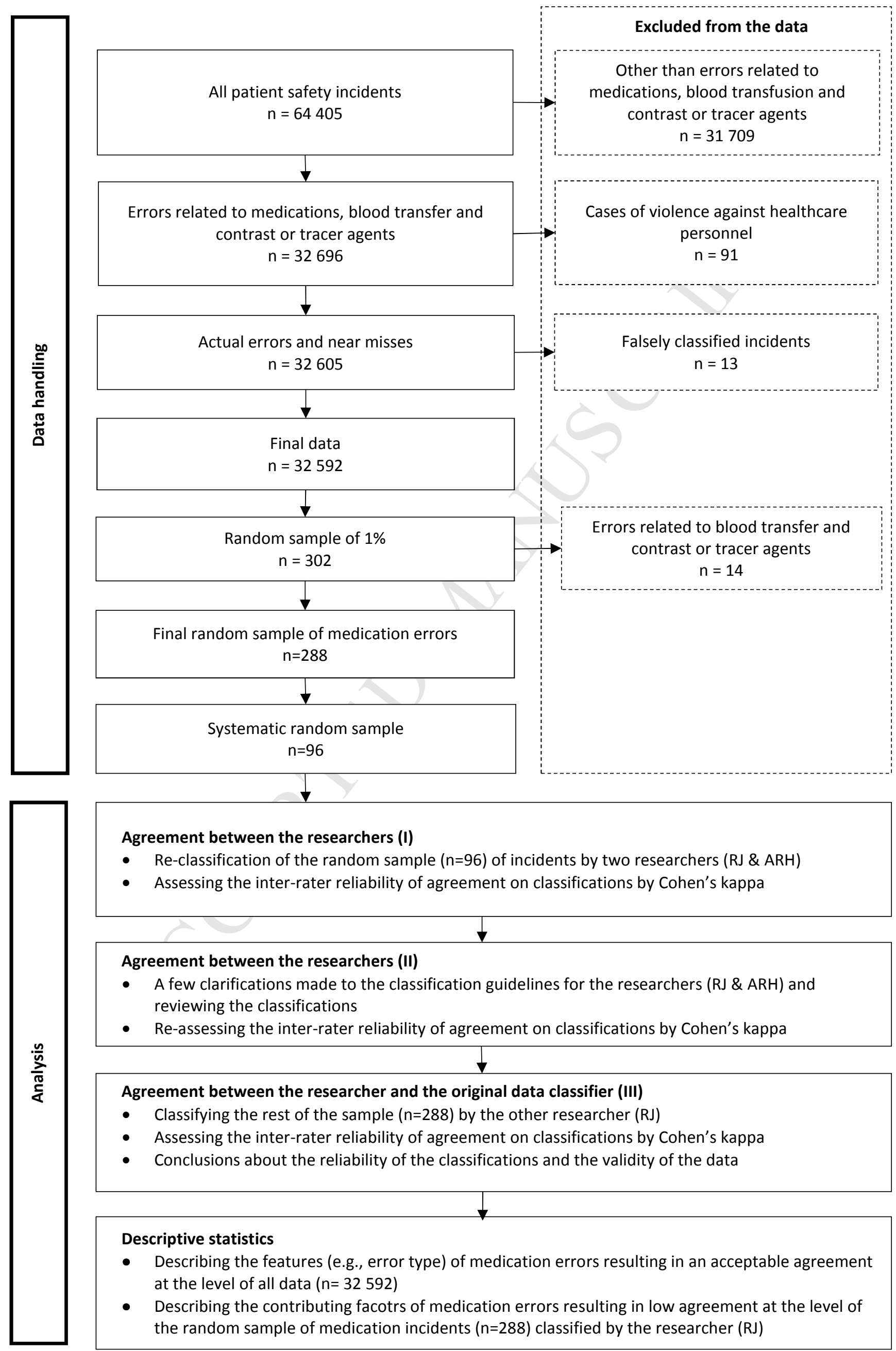




\section{Figure 1}

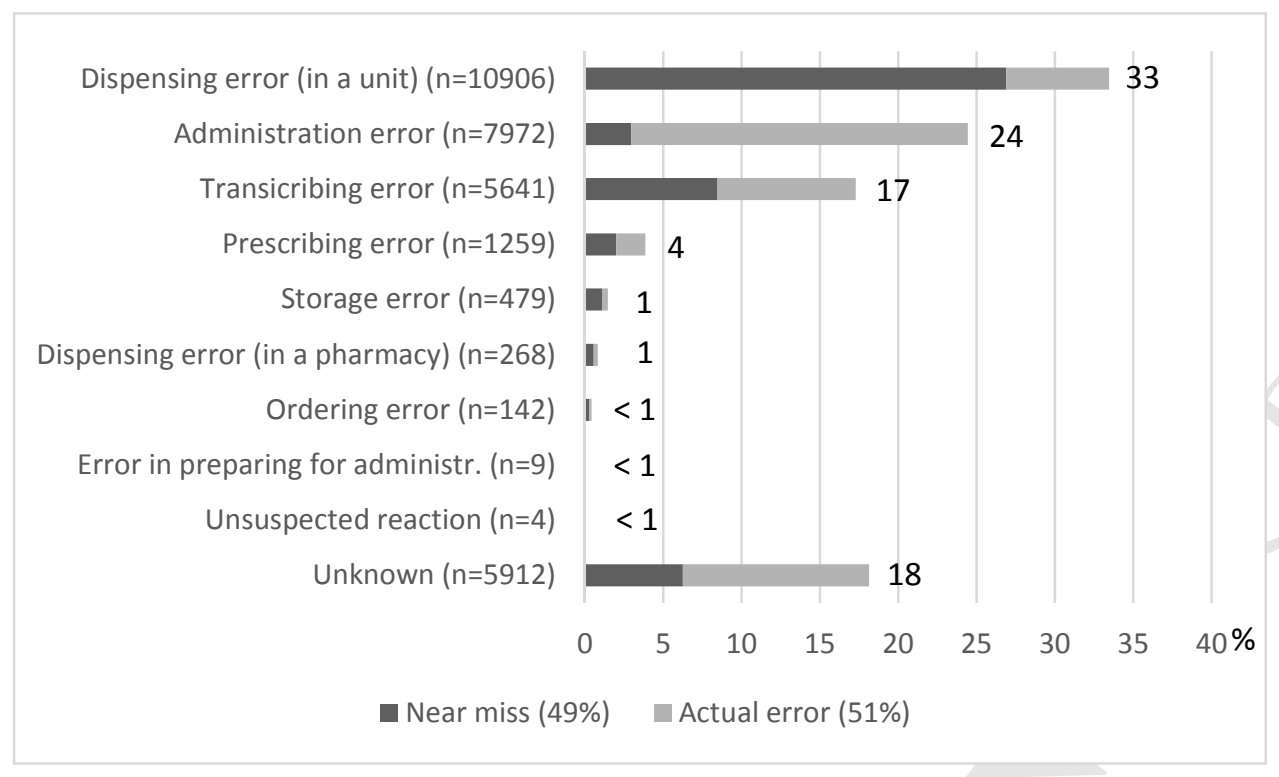

\section{Figure 2}




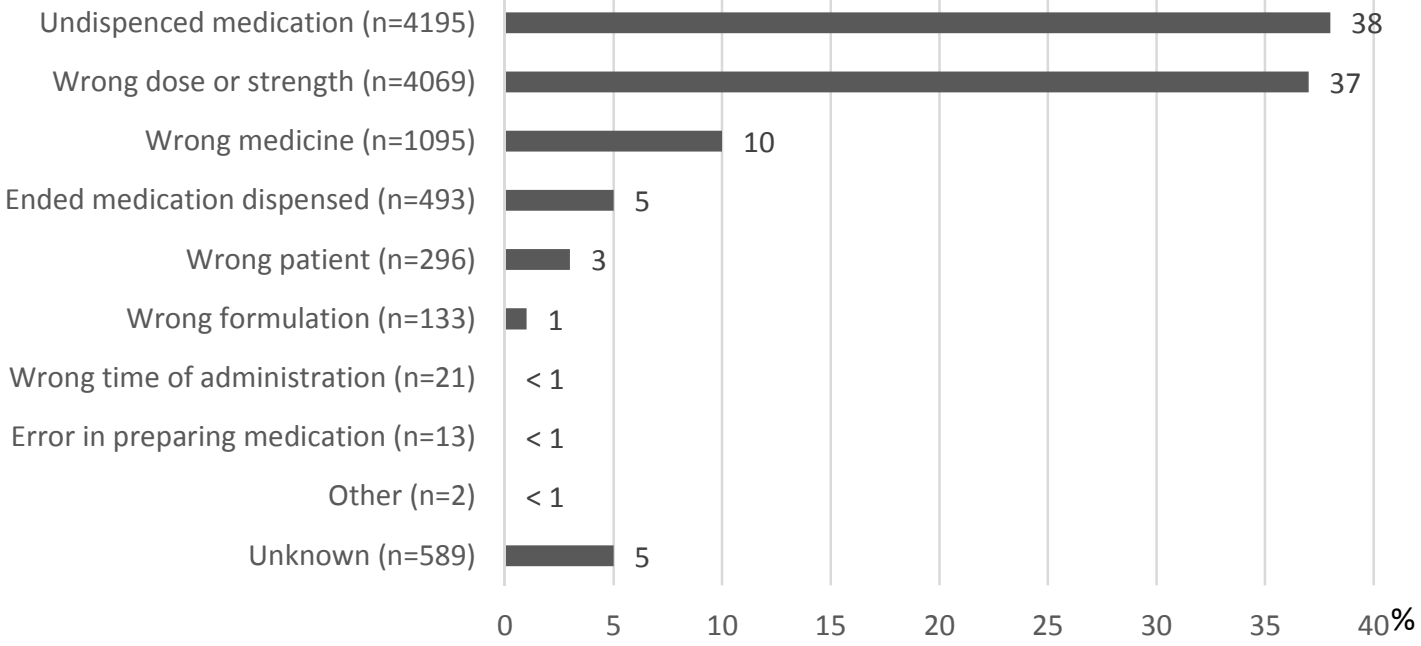

Defined types of dispensing errors ( $n=10906)$ as percentages

Medication unadministered $(n=2302)$

Wrong time of administration $(n=1366)$

Wrong dose or strength $(n=1331)$

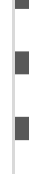

Wrong patient $(n=1025)$

Wrong medicine $(n=762)$

Wrong route of administration $(n=452)$

Ended medication administered $(n=314)$

$$
\begin{array}{r}
\text { Other }(n=25) \\
\text { Unknown }(n=394)
\end{array}
$$

)
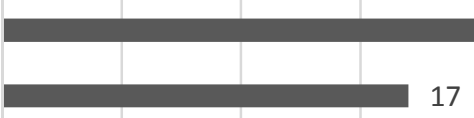

17
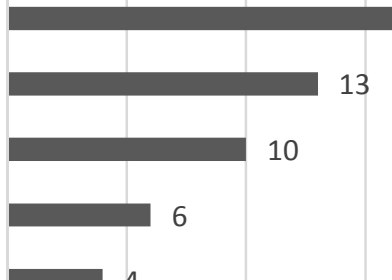

\section{6}

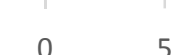

Defined types of administration errors $(n=7972)$ as percentages
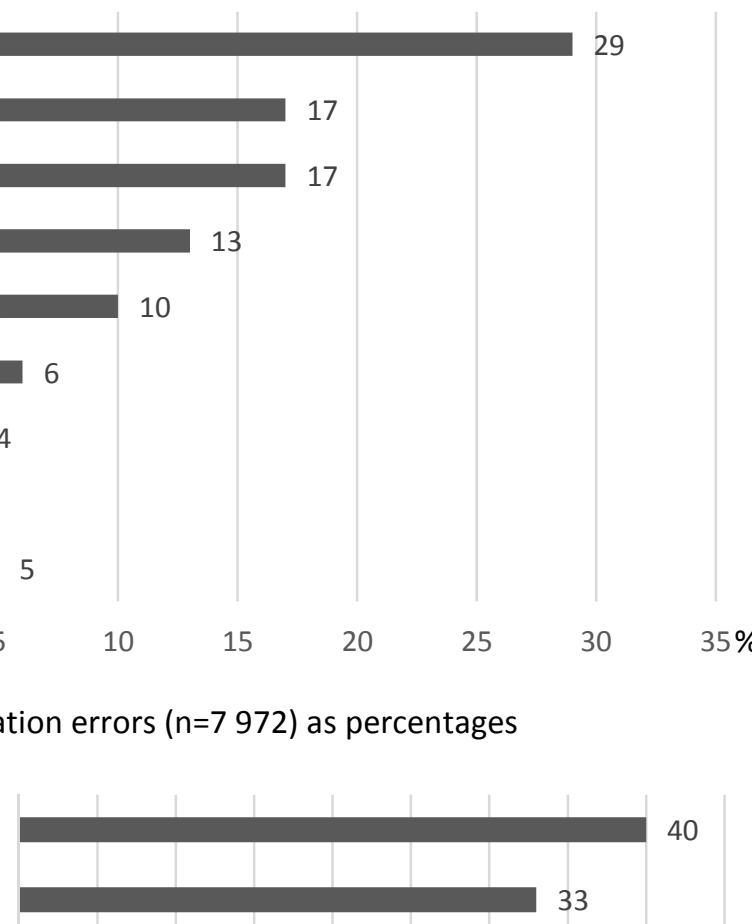
Medication undocumented $(n=2261)$
Wrong dose or strength $(n=1862)$

Ending time of medication undocumented $(n=508)$

Wrong medicine $(n=267)$

Wrond duration of medication treatment $(n=215)$

$$
\text { Wrong patient }(n=114)
$$

Wrong route of administration ( $n=36$ )

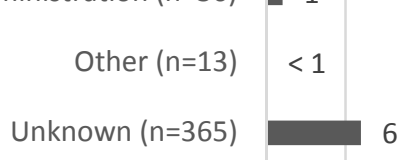

$0 \quad 5 \quad 10$

1520

25

$30 \quad 35$

\section{3}

40
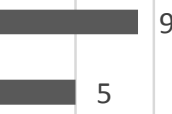

4

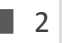


Figure 3.

\section{Narrative}

An 88-year old male patient with a broken hip was waiting for surgery. The patient received Oxynorm 6 $\mathrm{mg}$ s.c. at 08.55 prescribed by a doctor.

The patient became sleepy after one hour from receiving the medication. He experienced respiration arrests and was therefore transferred to the observation unit (also head ct was ordered and nothing pathological was found). The situation was corrected in the observation unit within a few hours. Later in the evening the patient was operated under spinal anesthesia. An epidural anesthetic infusion and p.o. paracetamol was administered for pain.

Consequently, the patient had a respiration arrest, causing a hazardous situation for the patient. The patient was transferred to observation and the operation was delayed. The instructional dose of Oxynorm s.c . for an elderly patient is $3 \mathrm{mg}$ which is half of the administered dose.

\begin{tabular}{|c|c|}
\hline $\begin{array}{l}\text { Contributing factors classified by the original } \\
\text { data classifier } \\
\text { - Education and orientation, } \\
\text { competence } \\
\text { - Knowledge and skills }\end{array}$ & $\begin{array}{l}\text { Contributing factors classified by the } \\
\text { researcher } \\
\text { - Education and orientation, } \\
\text { competence } \\
\text { - Knowledge and skills } \\
\text { - Working patterns and methods } \\
\text { - Availability and use of instructions, } \\
\text { guidelines and other written } \\
\text { information related to the task }\end{array}$ \\
\hline
\end{tabular}

Figure 4 


\section{ACCEPTED MANUSCRIPT}

Appendix 1 Information on the patient safety incidents collected by the HaiPro Incident Reporting System in the Pilot Phase of 2007-2009 (1).

Information provided by the healthcare professional reporting the incident

Reported through structured drop-down menus in the electronic HaiPro reporting form (2)

Date incident occurred

Unit of the healthcare professional reporting the incident

Unit were the incident occurred

Profession of the person reporting the incident

Date and time of the incident

Place of occurrence (e.g. operating room)

Nature of the incident (actual error, near miss or violation directed to personnel)

Incident type (e.g. dispensing error of a medicine)

Reported as open narratives in the HaiPro reporting form (2)

Description of the incident

- What happened and how the incident occurred

- What were the consequences for the patient and the unit

- Conditions at the time of the incident and other contributing factors

- Views of the reporting person on how similar incidents could be avoided in the future

Suggestions for action to prevent re-occurrence of the incident

Information classified by the data classifier (based on reported narratives) by a structured electronic 


\begin{tabular}{|l|}
\hline data classification form \\
\hline Defined type of the incident (e.g. a wrong medicine dispensed to a patient) \\
\hline Consequences for the patient and the unit \\
\hline Management of the incident situation \\
\hline Instant actions in the incident situation \\
Conditions at the time of the incident and other contributing factors (e.g. lack of information on the \\
\hline Information reported by the data classifier as an open narrative in the HaiPro system \\
\hline Actions to prevent the re-occurrence of the incident suggested by the reporter, or \\
explanation of why actions are not needed \\
\hline Description of how the suggested actions were executed \\
\hline
\end{tabular}

1. Ministry of Social Affairs and Health. Introduction of a reporting system for dangerous situations in health care. [Abstract in English]. Reports of the Ministry of Social Affairs and Health 2008:16.

2. Awanic Ltd. HaiPro - Patient safety incident report: http://83.150.87.4/haipro/20/lomake.asp?kieli=ENG. Accessed [215 Sep 2]. 